\title{
A TRADUÇÃO CRIATIVA DE PAULO LEMINSKI DO CARPE DIEM HORACIANO
}

\author{
Lívia Mendes Pereira ${ }^{1}$ \\ ${ }^{1}$ Universidade Estadual de Campinas, Campinas, São Paulo, Brasil
}

\begin{abstract}
Resumo: O presente trabalho estuda e divulga o "projeto tradutório" do poeta e tradutor curitibano Paulo Leminski, com enfoque nas traduções que este realizou de textos da tradição greco-romana. Como pode ser constatado na leitura de sua biografia e como pode ser recorrentemente percebido nos temas que frequentam sua obra, o autor foi um conhecedor e divulgador da Língua e da Literatura Latina. Estudado inicialmente no mosteiro São Bento, na cidade de São Paulo, esse idioma antigo constituiu uma importante fonte criativa revisitada e repensada durante toda sua carreira literária. Além de traduções feitas diretamente do Latim como as da Ode I, 11, de Horácio (1984), e do Satyricon, de Petrônio (1985), o trabalho com textos literários latinos também pode ser encontrado em obras como Metaformose e Catatau. Neste estudo, daremos uma atenção especial à tradução realizada por Leminski da ode Horaciana em seu diálogo com a tradução do mesmo poema realizada por seu amigo e principal referencial teórico, o poeta Augusto de Campos. Destacaremos, portanto, as principais características de cada tradução e as coincidências e diferenças existentes entre elas, pautando-nos na teoria da tradução como recriação, advinda dos ideais poundianos do make it new.
\end{abstract}

Palavras-chave: Tradição greco-romana; Tradução; Recriação; Paulo Leminski

\section{PAULO LEMINSKI'S CREATIVE TRANSLATION OF HORACE'S CARPE DIEM}

Abstract: The present work studies and disseminates the "translation project" of the poet and translator from Curitiba Paulo Leminski, with a focus on the translations that he made of the Greco-Roman texts tradition. 
It can be seen in the reading of his biography and it can be often perceived in the subjects which attend his work that the author was a knower and disseminator of the Latin Language and Literature. Originally studied by the author at the São Bento monastery located in the city of São Paulo, this ancient language was an important creative source revisited and rethought throughout his literary career. In addition to translations made directly from Latin, such as Ode I, 11, by Horace (1984) and Petronius's Satyricon (1985), the work with Latin literary texts can also be found in pieces as Metaformose and Catatau. In this study, we will pay special attention to the translation made by the poet of Horaces's Ode in its dialogue with the translation of the same poem by his friend and main theoretical reference, the poet Augusto de Campos. We will therefore highlight the main characteristics of each translation and the coincidences and differences between them, guided by the theory of translation as recreation, derived from the poundian ideals of make it new.

Keywords: Greco-Roman tradition; Translation; Recreation; Paulo Leminski

\section{O Carpe Diem Horaciano}

O poeta latino Horácio (Quintus Horatius Flaccus - 65-8 a. C.) foi um autor muito relevante para a poesia lírica romana e se destacou entre os demais poetas líricos da antiguidade. Sua poesia surgiu no cenário literário de Roma por volta de 35 a. C., primeiramente com o livro I das Sátiras, depois publicou o livro denominado Epodos, que consiste em 17 poemetos e então, finalmente, escreveu o livro II das Sátiras. Depois da publicação dos Epodos e das Sátiras, o poeta compôs quatro livros de Odes, dois de Epístolas e o Cântico Secular, em honra de Apolo e Diana.

As Odes são agrupadas em quatro livros e possuem grande importância na obra lírica de Horácio. O próprio poeta tinha consciência da importância do seu trabalho, pois assim expressou a permanência e a imortalidade de sua obra no último poema do terceiro livro: 
Exegi monumentum aere perennius

regalique situ pyramidum altius, quod non imber edax, non Aquilo impotens

possit diruere aut innumerabilis

annorum series et fuga temporum.

(Horace, O, III, 30, 1-5) ${ }^{1}$

Mais perene que o bronze um monumento ergui, mais alto e régio que as pirâmides, nem o roer da chuva nem a fúria de Áquilo o tocarão, tampouco o tempo ou a série de anos. Imortal em grande parte, a morte só de pouco de mim se apossará.

(Campos, A. (c))

Neste poema, assim como na tradição poética da antiguidade em que os poetas falam de si mesmos no último poema do livro e fazem expectativas sobre o futuro, Horácio constrói um poema monumental. Como enfatiza Nisbet e Rudd (364-367), este poema tem uma solidez que combina com o próprio assunto. Para os críticos (idem, ibdem), há uma construção generalizada de contrastes, que dão unidade ao poema, como a morte contra o crescimento, a transitoriedade contra a permanência e o temporal contra o poder literário.

Com grande variação de temas, assuntos, métrica e extensão, nelas o poeta canta a juventude, o amor, os prazeres do vinho e a alegria da vida. Todas elas foram escritas em uma linguagem elevada e ornamentada, sem exageros. Como afirma Kaimowitz (Horace IX (A)) em suas notas à tradução, toda essa temática é apresentada pelo olhar muitas vezes perplexo, mas também muito simpatizante de Horácio. O tradutor lembra também que a grandiosidade das odes horacianas é marcada pela influência de muitos poetas gregos

${ }^{1}$ HORACE. Horace, Odes et Epodes. Trad. F. Villeneuve. Paris: Les Belles Lettres, 2002.

Cad. Trad., Florianópolis, v. 39, nº 2, p. 71-94, mai-ago, 2019. 
como: Alceu, Safo e Píndaro, assim como a influência da filosofia helenística e, notavelmente, do epicurismo e do estoicismo. Assim como as influências gregas, o trabalho do poeta latino também reflete a influência de seus antecessores e contemporâneos, como Ênio, Catulo, Lucrécio, Virgílio e os escritores de elegia romana. Para Ancona (Horace xxiii a) essa característica no estilo de Horácio, ou seja, a incorporação de uma literatura anterior em um novo contexto, é particularmente interessante, pois as suas Odes também se tornaram uma importante fonte em excertos de escritores posteriores e funcionaram como figuras culturais nas artes e na literatura subsequentes a ele. Ademais, Ancona (Horace xxiv (a)) destaca que, enquanto Horácio estava escrevendo conscientemente em uma longa tradição literária, que possui muita influência de seus antecessores gregos, por outro lado seus poemas são muito contemporâneos e refletem de diversas formas o mundo romano do primeiro século a.C. em torno de sua complexidade social e política. Para a autora, decorrente dessa mistura entre tradição literária e sensibilidade contemporânea, há uma longa abrangência de temas e assuntos nas Odes, entre eles: poética, moralidade, filosofia, política, Roma, tempo, morte, erótico, banquetes e amizade, sendo portanto difíceis de serem categorizados.

Foi nas Odes que Horácio exprimiu algumas de suas principais ideias tópicas, que foram retomadas pela poesia de todas as épocas posteriores, revelando o desejo de aproveitar o momento presente e o elogio à moderação e à simplicidade. Para Ancona (Horace xxvii (A)) citações que foram retiradas das Odes de Horácio e se popularizaram mostram na fama do autor latino sua principal característica, o de ser aludido em diversos contextos diferentes; para a autora, essa característica faz com que se perca um pouco de seu significado original.

No presente trabalho o destaque será dado à Ode 11 do livro I, a ode em que Horácio apresenta a ideia tópica do carpe diem, muito divulgada desde então, e que já estava presente na lírica grega. Mesmo que o grande público não tenha lido integralmente a ode, o mote dela extraído foi amplamente divulgado por meio de 
traduções e adaptações da própria ode e também por estar presente na temática das obras de diversos autores ao longo da história literária. Sobre a popularidade do carpe diem horaciano, Ancona (Horace xxvii (B)) reitera que essa característica das Odes, de ser um material facilmente citável, faz com que Horácio seja utilizado fora de contexto. Nesse sentido, enquanto muitos poetas utilizam o carpe diem em seu contexto original, aqueles que conhecem a frase apenas em contextos de cultura popular podem se surpreender, pois não se trata apenas de um aviso filosófico sobre a efemeridade do tempo presente, mas faz parte de um poema que tem um eu-lírico específico e um destinatário em particular.

No prólogo de seu estudo, Francisco Achcar (13-21) também reitera essa característica horaciana, ao falar sobre o processo de escrita da Antiguidade, que para ele é uma forma particular de "arte alusiva", pois retoma um repertório tradicional e uma série de lugares comuns, organizando-os. O autor exemplifica, “[...] quando Horácio diz carpe diem ele está não só dizendo o que diz, mas está também aludindo a um paradigma de outras expressões do mesmo lugar-comum da poesia simposial" (Achcar 18). Portanto, seu poema está inscrito em um gênero, que faz com que o leitor familiarizado crie uma expectativa em formular um conjunto de tópoi, organizados em esquemas já conhecidos.

Dessa forma, Achcar conclui que

a novidade e a propriedade com que esses lugares-comuns são expressos, a habilidade com que são correlacionados ou a originalidade com que são exploradas novas possibilidades de organização - nisso consiste parte essencial dessa arte de que Horácio foi mestre exímio (18)

Apresentarei aqui o texto latino horaciano acompanhado da "tradução de serviço", feita por mim. Entende-se como "tradução de serviço" uma leitura atenta e uma descrição do sistema gramatical do texto latino, que se faz necessária devido à enorme distância 
entre o tradutor moderno e o idioma antigo, e, nesse caso, revela a leitura que o estudioso de latim fez do texto antigo em questão. Com a apresentação da "tradução de serviço" não pretendo expressar o texto latino em um único sentido em língua portuguesa, contudo procuro divulgar a minha leitura do texto, que embasará o trabalho de análise. Como destacou Longo (68), este processo de tradução "é o resultado de uma prática metalinguística em que se busca transpor os componentes léxico e morfossintático do latim para o português a fim de ajudar o leitor a ter uma primeira compreensão do texto". Dessa forma, a "tradução de serviço" funciona como uma demonstração da leitura do texto latino, a partir de um ponto de vista, não se tratando, portanto, de uma leitura fechada em si mesma e não se pretendendo, assim, uma leitura fiel ao texto de partida. Como podemos constatar, em todo trabalho de crítica tradutória o pesquisador deve estar apto a uma leitura atenta e dedicada do texto de partida, porém, em se tratando do texto latino e, diferente do que acontece com as línguas modernas, essa leitura não é fluente, por isso a necessidade de se obter uma "tradução de serviço" como apoio à análise e como indicação da leitura que o estudioso concebeu do texto antigo. Outra marca importante da "tradução de serviço" é a de se apresentar para os leitores leigos em língua latina a leitura do próprio pesquisador, que, a partir daí, poderá ser cotejada com outras traduções do mesmo texto em língua portuguesa.

Feitas essas considerações, destacamos o texto latino e a respectiva "tradução de serviço":

Tu ne quaesieris, scire nefas, quem mihi, quem tibi finem di dederint, Leuconoe, nec Babylonios temptaris numeros. ut melius, quidquid erit, pati. seu pluris hiemes seu tribuit Iuppiter ultimam, quae nunc oppositis debilitat pumicibus mare Tyrrhenum: sapias, vina liques et spatio brevi spem longam reseces. dum loquimur, fugerit invida aetas: carpe diem quam minimum credula postero. (Horace, O, I, 11) 
Tu não procures, saber é ímpio, a mim ou a ti que fim os deuses tenham dado, Leucônoe, nem procures os números babilônicos; tão melhor é suportar tudo o que será.

Quer Júpiter tenha concedido muitos invernos, quer o último

que, nas rochas opostas, agora, debilita o mar Tirreno:

sejas sábia, coes os vinhos e no espaço breve

cortes a longa esperança. Enquanto estamos falando, terá fugido

o tempo invejoso. Colhe o dia, quanto menos crédula no que vem depois.

O poema se inicia com uma advertência à interlocutora do eu-poético, Leucônoe, essa advertência remete à consulta aos astrólogos como adivinhação do destino e do futuro. A prática astrológica era recorrente na época de Horácio e provocou algumas leis repressivas para controlá-la; o eu-lírico desaconselha a moça a ir à procura de prever a morte e, assim como demonstrou Achcar (89), inicia o poema com um tom grave ao utilizar como primeira palavra 0 pronome $t u$, em um registro não coloquial, ou seja, o imperativo ne quaesieris e, logo em seguida, a fórmula religiosa scire nefas, que nesse caso se refere a algo proibido ao interferir nas leis divinas.

Antes de indicar o nome da interlocutora, o eu-lírico indica a proximidade existente entre eles ao incluir-se ao conhecimento de seu destino pelos deuses na frase: quem mihi, quem tibi, finem di dederint $^{2}$. O vocativo, Leucônoe, indicado logo ao centro do segundo verso, entre muitas suposições feitas por teóricos e leitores, é considerado como a junção das palavras gregas leukós (ingênuo) e nous (espírito), ou seja, a Leucônoe do poema remete àquela de "alma cândida”, que em sua ingenuidade acredita na adivinhação astrológica.

No três versos seguintes (versos 3, 4 e 5), o eu-lírico adverte sobre os cuidados indevidos com o futuro e aconselha que é preciso

2 "Qual o fim que a mim e a ti os deuses tenham dado". 
conformar-se com aquilo que virá, indicando o poder dos deuses, na figura de Júpiter, em controlar o destino, sendo este momento o primeiro de muitos ou apenas o último deles.

Nos versos finais (versos 6, 7 e 8) há uma sequência de exortações ao prazer, sempre indicando o aproveitamento do tempo presente, sem acreditar no amanhã. O primeiro convite é feito com o uso do termo latino sapias, segunda pessoa do singular do presente do subjuntivo do verbo sapio, convidando à sabedoria e à prudência. Em seguida, o eu-lírico sugere uina liques, que se refere ao hábito romano de coar o vinho antes de bebê-lo, purificando-o. Como lembra Achcar (92), Horácio escolhe o verbo liquo, para enfatizar o processo de filtragem do vinho, pois também era comum entre os romanos outro procedimento, que consistia em deixar o vinho descansando durante a noite para que fossem evaporados os sedimentos e se aproveitasse o verdadeiro sabor genuíno. Porém, no poema o eu-lírico não deixa outra alternativa, pois acredita que deve-se realizar o consumo imediato, pois não se sabe se haverá amanhã para que ele seja degustado. Em seguida, o eu-lírico adverte: spem longam reseces ${ }^{3}$. Nesta sentença o verbo resecare funciona como ligação ao próximo verbo, que foi imortalizado como o grande momento do poema, carpere, enquanto o primeiro convida a "cortar", de forma abrupta e direta a esperança, o segundo induz a "colher", como algo vagaroso, ou seja, o eu-lírico convida Leucônoe a "colher o dia", assim como colheria uma rosa ou um fruto. O verbo carpere, portanto, funciona como o grande convite em aproveitar o dia, como se fosse o último, longe de qualquer esperança no que virá, de forma singela, mas também objetiva.

Como conclui Achcar (97), baseado em estudos da lírica horaciana, o poema do carpe diem faz parte dos poemas de "argumentação lírica", ou seja, "poemas que procuram provar, demonstrar, chegar a uma conclusão" e é exatamente isso que o poema de Horário apresenta, a demonstração de como não se fiar no amanhã, ou até mesmo no passado e apenas viver o instante presente.

3 "Corta a longa esperança".

Cad. Trad., Florianópolis, v. 39, no 2, p. 71-94, mai-ago, 2019. 


\section{Tradução como recriação: O Carpe Diem recriado}

Por ser um poema muito conhecido, a Ode I, 11 possui inúmeras traduções para a língua portuguesa, tanto de poetas portugueses como de poetas brasileiros, para citar alguns exemplos, traduziram o poema: André Falcão de Resende, Filinto Elísio, Elpino Duriense, Marquesa de Alorna, Paulo Henriques Britto, Augusto de Campos e Paulo Leminski. A maioria das traduções utilizam os versos mais tradicionais, hexassílabos, decassílabos, ou dodecassílabos. Diferente dessa tradição, Augusto de Campos e Paulo Leminski transpuseram o poema em versos livres, empregando a técnica da visualidade, cara ao Movimento Concretista do qual Augusto foi um dos fundadores, juntamente com seu irmão Haroldo e o amigo Décio Pignatari e pelo qual Leminski se influenciou largamente, seguindo seus paradigmas literários e tradutórios.

No presente trabalho irei comentar os procedimentos teóricos tradutórios de Paulo Leminski, por meio da influência do make it new poundiano e da "recriação em tradução" cunhada no Brasil pelos poetas concretistas e, a partir daí, demonstrar suas escolhas na tradução do poema horaciano.

Sobre as concepções tradutórias de Ezra Pound diz Augusto de Campos:

Pound não só examinava com uma "nova sutileza de olhos" os escritores de outras épocas e latitudes, mas os vertia para a língua inglesa, ainda, ou principalmente, quando apresentavam problemas quase intransponíveis para a tradução. Adotou o lema confuciano: MAKE IT NEW (renovar), para dar nova vida ao passado literário via tradução. [...] Um aspecto inconfundível da arte de traduzir poundiana é a ausência de ortodoxia, a extraordinária liberdade de suas recriações (Campos 20-21(B)).

Os projetos tradutórios dos irmãos Campos e de Leminski passam pelo ideal poundiano, que faz com que a tradução seja igua- 
lada à criação, se confundindo em um único objetivo que é o de renovar, make it new. O poeta norte-americano traduziu a Ode horaciana em questão, trata-se de uma importante referência para os poetas brasileiros:
Ask not ungainly askings of the end
Gods send us, me and thee, Leucothoe;
Nor juggle with the risks of Babylon,
Better to take whatever,
Several, or, last, Jove send us. Winter is winter,
Gnawing the Tyrrhene cliffs with the sea's tooth.
Take note of flavors, and clarity's in the wine's manifest.
Cut loose long hope for a time.
We talk. Time runs in envy of us,
Holding our day more firm in unbelief.
(Pound 9)

Em comentário sobre a tradução realizada por Pound, da Ode I, 11 de Horácio, Davidson (33) ressalta que a tradução é fiel ao sentido do poema latino, mas traz para o leitor de língua inglesa uma maior concisão, com isso o tradutor vai além da superfície do poema latino e oferece uma leitura iluminada deste. Essa leitura de Pound é muito importante, segundo Davidson (34), pois especialmente nas odes de Horácio a leitura não pode ser feita pelo senso comum, diferente disso, nas Odes o leitor deve conectar os elementos e descobrir na estrutura central os sentidos do poema. Davidson (idem, ibdem) ressalta duas passagens em que Pound não traduz exatamente as frases como está no texto latino, porém transfere a mesma imagem e o mesmo efeito alcançado por Horácio; trata-se dos versos 4 e 5, primeiramente ao dizer apenas "Winter is winter" ele está implicitamente retomando a ideia do texto latino

4 "inverno é inverno"

Cad. Trad., Florianópolis, v. 39, no 2, p. 71-94, mai-ago, 2019. 
de que "devemos aceitar aquilo que nos é dado, seja uma experiência primeira ou última"; depois, na imagem do mar Tirreno que se choca com as rochas, no texto latino o autor cria a imagem de um mar que está sendo debilitado, enfraquecido (debilitat mare $)^{5}$; Pound inverte esta imagem, assim sendo, em sua tradução a rocha está sendo corroída pelo mar "Gnawing the Tyrrhene cliffs with the sea's tooth", e utiliza a imagem do 'dente' para enfatizar a brutalidade da ação de corroer ou roer. Por fim, Davidson comenta a tradução de Pound dos dois últimos versos do poema horaciano, que é finalizado como um resumo de todas as ideias que foram colocadas durante todo o poema, com a presença da consagrada expressão "carpe diem"; Davidson (35) destaca o foco que Pound oferece à imagem do 'tempo', conectando as duas ideias presentes no texto de Horácio. Percebe-se, portanto, que Pound também oferece um sumário das ideias do poema, mas não retoma a tradução literal da expressão latina.

Com essa breve análise da tradução poundiana do poema horaciano do "carpe diem", pudemos constatar como o tradutor estadunidense colocou em prática sua teoria tradutória do make it new. Os poetas concretistas brasileiros retomaram em seus projetos tradutórios a principal característica desta teoria, ou seja, o princípio de não apenas 'renovar' a linguagem, no sentido de atualizá-la para a linguagem mais atual, porém fazer do 'novo' algo que seja 'inovador', não perdendo as características da obra de partida, mas também, incorporando características autorais, diferentes daquelas já estabelecidas no texto original, no produto final do texto de chegada.

As traduções da Ode, I, 11 horaciana realizadas pelos poetas Augusto de Campos e Paulo Leminski foram produzidas quase que simultaneamente. A tradução de Leminski foi publicada em 1984 na revista Remate de Males, em uma edição especial sobre tradução, e a de Augusto na revista Código 10, em 1985, um ano depois. Dessa forma, por se tratarem de poetas que seguem os

\footnotetext{
5 "quae nunc oppositis debilitat pumicibus mare/ Tyrrhenum"

6 "corroendo as rochas do Tirreno com o dente do mar"
} 
mesmo paradigmas tradutórios, de influência poundiana, e por terem sido produzidas na mesma época, as duas traduções são muito correspondentes.

Primeiramente, destacarei duas passagens relevantes na tradução de Augusto. Segue a tradução na íntegra:

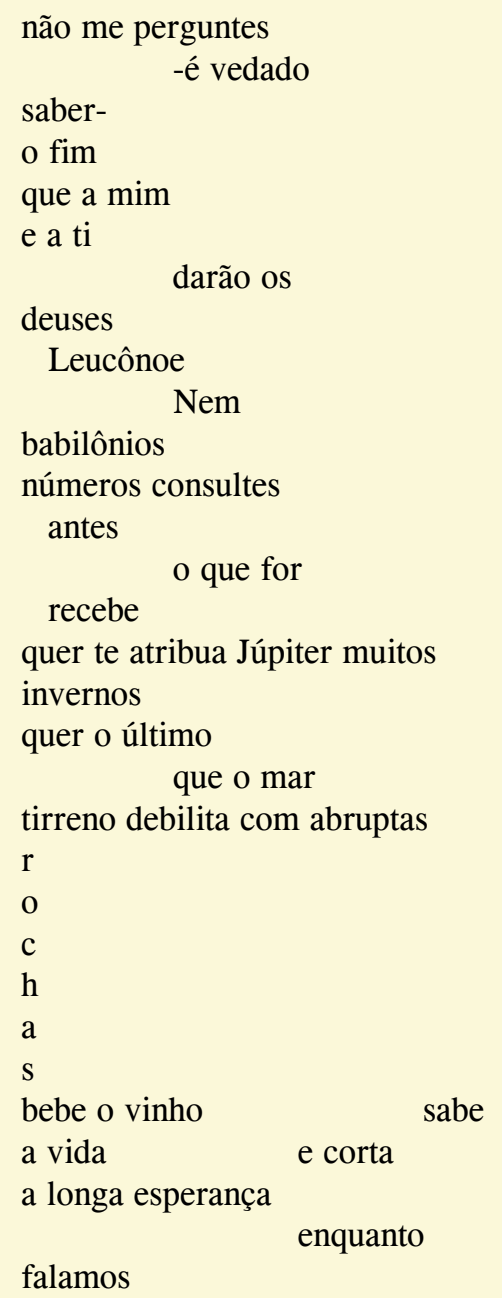




\author{
foge \\ invejoso \\ o tempo: \\ curte o dia \\ desamando amanhãs
}

(Campos, A. (A))

Inicialmente, com a utilização do termo "rochas", colocado na vertical, produzindo um sentido imagético, como na tradução de Pound, das rochas que são golpeadas pelo mar agitado, Augusto também remete ao seu sentido metafórico referente ao tema do carpe diem, ou seja, esta imagem da 'rocha' que permanece firme, mesmo com a passagem do mar, representa a vida daquele que permanece sereno, mesmo com a passagem do tempo. Outra característica que se destaca na tradução de Augusto é a utilização da linguagem mais formal: a utilização da conjugação verbal na $2^{a}$ pessoa do singular do Imperativo ('perguntes', 'consultes', 'bebe', 'sabe', 'corta'); vocabulário de registro mais erudito ('vedado', 'consultar', 'atribuir', 'debilitar', 'abruptas', 'desamar', 'amanhãs').

Apenas no final do poema há um registro informal na escolha do verbo latino carpere; Segundo o dicionário Aulete, 'curtir' é um termo coloquial e popular do português do Brasil e significa "divertir-se com; desfrutar", dessa forma, Augusto fecha o poema com uma escolha totalmente informal, porém com um termo que remete ao original latino e não perde o proposital convite ao desfrute singelo e despropositado do tempo presente, nas próprias palavras de Augusto: “desamando amanhãs".

Passando para a tradução leminskiana, logo de início percebemos a mesma cadência rítmica presente na tradução de Augusto, causada pelo jogo imagético dos trechos curtos e distribuídos no espaço em branco, que levam o leitor a entrar no ritmo do poema de forma inconsciente, conduzido pelos versos.

Segue a tradução de Paulo Leminski: 


\section{Nem me pergunte}

Leuconoe

saber não presta

que fim os deuses nos preparam

nem arrisque

$$
\text { números de Babel }
$$

como se fosse o máximo - o que vier: fature

se o Pai te concedeu vários invernos

ou o último

agora o mar tyrrheno cepilha pedras de naufragar

filtre o vinho

sorva os côos

$$
\begin{aligned}
& \text { prazo breve } \\
& \text { corta } \\
& \text { a espera }
\end{aligned}
$$

a era já era

antes do tempo de dizer

estamos conversados

pega este dia

$$
\text { crer no próximo }
$$

não vale um nihil

(Leminski (A))

O maior diferencial entre a tradução de Leminski e as demais traduções em língua portuguesa, mesmo a realizada por Augusto, está demarcado pela máxima concisão, influenciada pela sua própria experiência poética, principalmente de influência haicaísta, marcada pela simplicidade e também pelo uso da linguagem extremamente informal e coloquial. Leminski mescla o uso da conjugação verbal na $3^{\mathrm{a}}$ pessoa do singular do Imperativo, uso informal ('pergunte', 'arrisque', 'fature', 'filtre', 'sorva') e na $2^{\text {a }}$ pessoa do singular do Imperativo, uso mais formal ('corta', 'pega').

Como afirma Santana (2002), a postura 'pop’ de Leminski, muitas vezes mais preocupado em atingir um maior público, faz com que o poeta vulgarize e simplifique os termos do texto de partida 
em suas traduções. Isso pode ser constatado em toda a sua obra no que se refere à língua latina, tanto nas traduções diretas quanto nas referências greco-romanas. Leminski utiliza a língua da Antiguidade clássica, que muitas vezes é tida como alto padrão da linguagem e associada ao academicismo, de forma simples, tirando-a do pedestal e incluindo-a na linguagem popular. O próprio poeta sugere que sua facilidade em atingir um nível coloquial da linguagem está relacionada a sua experiência com o jornalismo e a publicidade; em uma das cartas a Régis ele afirma: "essa minha experiência com jornalismo cultural/ ou contracultural/ me libertou de um monte de vícios letrados" (Leminski and Bonvicino 47). Mais do que afirmar essa característica linguística de suas obras, o poeta fazia disso uma forma de orientar sua geração e como um verdadeiro movimento contracultural, de quebra com os parâmetros pré-concebidos. Em outra carta, ele encoraja e orienta o poeta Régis a fazer o mesmo em seus textos: "coloque-se na pele do leitor comum/médio... fisgue-o.../ não podemos ficar choramingando que os grandões da zona norte não nos deixam abrir a boca... tem que ir lá e gritar... guerrilha, guerreiro!" (Leminski and Bonvicino 103).

Essas características podem ser percebidas de forma clara na tradução do carpe diem leminskiano, o poeta adquire uma liberdade extrema, traduzindo os trechos latinos de forma menos literal possível e realmente recriando um novo poema a partir do mote latino horaciano.

A tradução do poema se inicia de forma extremamente informal com o uso do adverbio 'nem' e a utilização do verbo 'prestar', dois termos muito presentes na linguagem coloquial do Brasil, referindo-se a algo que não vale a pena, traduzindo o latino scire nefas. Dessa forma, o poeta transfere o sentido do primeiro verso latino de forma exata para o português, porém desfazendo o tom grave do texto latino, de forma que, logo de início, o poema tenha um tom de diálogo íntimo entre o eu-poético e a personagem Leucônoe. Porém, essa escolha faz com que se perca o matiz religioso de nefas.

Nos versos seguintes, Leminski escolhe o verbo 'arriscar' para traduzir o latino temptare; com essa escolha o poeta deixa explí- 
cito o sentido da crença no jogo ou nos astros, ou seja, expor-se às circunstâncias da sorte, de algo que não há uma certeza, e logo em seguida traduz o adjetivo latino Babylonius pelo substantivo em português "Babel" e acrescenta um verso que não possui correspondência em latim, "como se fosse o máximo". Com esse acréscimo o poeta enfatiza a crença ingênua de Leucônoe nos astros e também, de forma irônica, a opinião incrédula do eu-poético diante de tal confiança.

No próximo trecho Leminski consegue a máxima concisão: transportando o sentido completo do latim "ut melius, quidquid erit, pati" , Leminski apenas diz: "o que vier: fature", utilizando mais uma vez um verbo coloquial no registro do português do Brasil, "faturar", que significa no sentido figurado "ganhar dinheiro; obter vantagens", ou seja, o poeta interpreta para a linguagem coloquial o texto latino, já inserindo a máxima do carpe diem de aproveitar ao máximo tudo que vier.

Em seguida para a conjunção latina repetida por Horácio seu... seu, que em português tem um sentido da conjunção alternativa 'quer...quer', Leminski utiliza a conjunção condicional 'se' juntamente com a alternativa 'ou'; neste mesmo trecho para o termo latino Iuppiter, relativo ao deus Júpiter, que é por excelência o grande deus do panteão romano, Leminski traduz em português por 'Pai', com letra maiúscula, que religiosamente, segundo o dicionário Aulete, significa “designação bíblica da divindade, responsável pela criação de tudo e de todos os seres, esp. o homem; DEUS”. Nesse sentido, o poeta transfere o sentido latino para a cultura cristã, utilizando um termo referente ao "deus maior" na cultura brasileira.

Porém, logo em seguida, mantém a transcrição em língua portuguesa do termo latino mare Tyrrhenum, referente ao mar que banha a costa ocidental da Itália, ao dizer "mar tyrrheno". Essa é uma característica do projeto tradutório leminskiano: ao mesmo tempo em que ele atualiza certos termos, em outros momentos, prefere manter o termo da língua estrangeira, causando um estranhamento

7 "tão melhor é suportar tudo o que será".

Cad. Trad., Florianópolis, v. 39, no 2, p. 71-94, mai-ago, 2019. 
no leitor, para que ele saiba que se trata de uma tradução, mesmo que recriada em uma nova língua.

No final do poema, percebemos que o poeta utiliza um termo latino nihil, que significa "nada, coisa nenhuma", sendo que este termo latino não está presente na ode horaciana. Nesse caso, portanto, ele causa um estranhamento, utilizando um termo da língua estrangeira como forma estética, lembrando novamente que se trata de uma tradução do texto latino, por isso a referência à língua latina.

No trecho "cepilha pedras de naufragar", Leminski poetiza o trecho horaciano "quae nunc oppositis debilitat pumicibus marem Tyrrhenum", utilizando o verbo formal em língua portuguesa 'cepilhar', que significa no sentido denotativo "dar polimento a; brunir; limar; lustrar", mas também no sentido figurado "procurar aproximar da perfeição; tornar mais apurado; aperfeiçoar”. Com a utilização desse termo o poeta consegue transmitir ao mesmo tempo a imagem do mar limando as pedras e a metáfora relacionada à vida, que com as batidas do 'tempo', aqui metaforizado pelo movimento do mar, faz com que nos aperfeiçoemos.

No próximo verso, para o trecho latino vina liques, Leminski traduz duas vezes, primeiro literalmente "filtre o vinho", utilizando o verbo 'filtrar' referente ao verbo latino liquere, e novamente diz "sorva os côos", utilizando o verbo 'sorver', que significa, segundo o dicionário Aulete, "beber aos sorvos ou aos poucos, em pequenos goles; beber vagarosamente", e o substantivo 'côos' que se refere àquilo que foi filtrado. Deste modo, Leminski amplifica o sentido de um trecho latino ao aconselhar a filtrar o vinho e depois bebê-lo vagarosamente, deixando clara novamente a metáfora referente à tópica do carpe diem e referenciando ao costume latino de filtrar o vinho para bebê-lo de forma imediata.

No próximo trecho, "spatio brevi/ spem longam reseces", Leminski traduz como que em um haikai, independente do restante do poema, ignorando o adjetivo latino longus, da seguinte forma:

\footnotetext{
8 "que, nas rochas opostas, agora, debilita o mar Tirreno".

9 "no espaço breve/ corta a longa esperança".
} 
prazo breve

corta

a espera

E continua utilizando esse estilo no restante do poema, de forma menos literal e mais concisa, agora, com um tom mais poético e interpretativo.

Para o trecho latino "dum loquimur, fugerit invida aetas"10, Leminski diz:

a era já era

antes do tempo de dizer

estamos conversados

E finalmente, terminando o poema com o verso derradeiro, que denomina toda a tópica que ficou reconhecida como um modelo de vida e filosofia, traduz o último verso latino, "carpe diem quam minimum credula póstero"11, quase que resumindo também todo o sentido do carpe diem em um simples e conciso haikai, utilizando para o verbo latino carpere o verbo em língua portuguesa "pegar", que possui um amplo significado como "segurar ou agarrar; apanhar ou buscar; alcançar ou usufruir" e que traduz de forma simples e direta o sentido de "colher algo" advindo do verbo latino:

pega este dia

crer no próximo

não vale um nihil

10 "enquanto estamos falando terá fugido o tempo invejoso".

11 "Colhe o dia, quanto menos crédula no que vem depois".

Cad. Trad., Florianópolis, v. 39, no 2, p. 71-94, mai-ago, 2019. 


\title{
3. Considerações finais
}

Analisada a tradução leminskiana, amparando-nos nas teorias de tradução como "recriação", podemos concluir que Leminski atingiu o objetivo de seu projeto tradutório. Os poetas tradutores conseguiram recriar o poema horaciano em língua portuguesa dentro do contexto em que estava inserido e, ao mesmo tempo, não excluiu as características presentes no poema latino. Lembramos que nesta análise levou-se em consideração as escolhas tradutórias de poetas tradutores em seu contexto de produção e de formação literária, buscando evidenciar suas próprias concepções tradutórias.

Tratando-se de um poema devemos lembrar as palavras de Haroldo de Campos sobre a intraduzibilidade na poesia:

\begin{abstract}
Tradução de textos criativos será sempre recriação, ou criação paralela, autônoma, porém recíproca. Quanto mais inçado de dificuldades esse texto, mais recriável, mais sedutor enquanto possibilidade aberta de recriação. Numa tradução dessa natureza, não se traduz apenas o significado, traduzse o próprio signo, ou seja, sua fisicalidade, sua materialidade mesma [...]. O significado, o parâmetro semântico, será apenas e tão-somente a baliza demarcatória do lugar da empresa recriadora (Campos, H. 35)
\end{abstract}

Dessa forma, é essa "recriação do próprio signo em sua materialidade mesma" que percebemos nas traduções destacadas. Enfatizamos que todo os repertórios de conceitos tradutórios seguiram as concepções dos poetas concretistas Haroldo e Augusto de Campos e Décio Pignatari, como também a teoria poundiana do make it new. Destacamos que ambas dispõem os versos no espaço em branco como que sugerindo um ritmo e uma melodia; essa técnica foi denominada por Haroldo de Campos de "reimaginação" e leva em consideração a topografia e a tipografia do texto. Como explica Faleiros (43), esta técnica cria "um texto apreendido imediatamente na globalidade de sua imagem tipográfica, sendo em geral, a pri-

Cad. Trad., Florianópolis, v. 39, no 2, p. 71-94, mai-ago, 2019. 
meira leitura, uma leitura global. A disposição das manchas indica também caminhos de leitura, além de esconder ou dar mais visibilidade a determinadas recorrências no poema”. Nas duas traduções, as sequências rítmicas transportam para a língua portuguesa a concisão típica da língua latina, como também o ritmo do poema horaciano, que em diversos momentos prolonga os períodos de um verso a outro causando um efeito semelhante ao enjambement.

Salientamos também uma diferenciação entre elas, que procuramos demonstrar na análise do projeto tradutório do poeta curitibano, que se diferencia de seus antecessores na utilização de uma linguagem acentuadamente mais prosaica e coloquial e no teor de um humor lírico-sensorial, atingindo um novo público e uma nova geração de leitores. Como destacamos na análise, comparativamente, Augusto de Campos utiliza uma linguagem mais formal e um tom mais poético e menos prosaico em sua tradução, que restringe, portanto, seu público alvo.

Assim como afirmou Leite (67) "como tradutor, o poeta curitibano tinha plena consciência da materialidade do signo verbal. Afinal, quem traduz tem obrigatoriedade, de 'pensar' os conceitos dentro da língua original para expressá-los com e por meio de um novo veículo linguístico", esses preceitos estão presentes na atividade tradutória e nas concepções teóricas do poeta.

Outra referência à utilização da linguagem coloquial como forma de imprimir autoria poética e colocar em prática a "recriação" utilizada por Leminski é demonstrada por Santana \& Galindo (2010) ao comentarem a tradução de Giacomo Joyce, a partir da lembrança do elogio de Antônio Houaiss falando sobre esta tradução. O estudioso e tradutor diz que Leminski soluciona dificuldades de linguagem de forma muito precisa ao transpor para a nova língua, mesmo parecendo arbitrário, isso constitui um "direito ao autor" que deve ser valorizado "aos que ousam (e conseguem) traduções dessa natureza" (Houaiss apud Santana \& Galindo, 91).

Muitas dessas concepções ficaram registradas principalmente no livro Ensaios e Anseios Crípticos (2012), em que Leminski afirma no artigo "Trans/paralelas": 
Traduzir de uma língua para outra é apenas um caso particular de tradução. A possibilidade da tradução está na própria raiz da natureza do signo [...] a vida da cultura é um processo de traduções contínuas e constantes, em que traduções se transformam em novos originais, por sua vez, traduzidos, para repertórios mais altos ou mais baixos, vindo a constituir originais novos, e assim por diante (Leminski 285b)

Ou seja, Leminski procurou realizar sua tradução a partir dessas premissas, as quais acreditava, de que compor e/ou traduzir poesia é apenas uma nova forma de interpretar uma cultura ou uma visão de mundo, que também são constituídos por signos. Pudemos perceber esses critérios efetivados na materialidade da língua explorada pelo tradutor de forma precisa em sua tradução.

Sobre a autoridade que o tradutor imprime na tradução, Laranjeira (124) diz que "o sujeito da tradução opera o trabalho do traduzir que gera um texto seu. Mas esse trabalho se faz a partir da leitura de um texto que não é seu, leitura que é uma expedição às profundezas do texto alheio para roubar-lhe a centelha viva do fogo sagrado: a significância". Nesse sentido pensamos e analisamos o trabalho tradutório leminskiano, vislumbrando um poema que "é e não é o original", um trabalho de produção com toda sua complexidade, distante de ser apenas uma transferência da língua de partida para a de chegada.

Sendo assim, a importância do destaque nas traduções de Augusto de Campos e de Paulo Leminski se reflete em podermos visualizar de forma clara e precisa essa dialética tradutória, como destaca Laranjeira (124-125) citando Georges Steiner de que a ambivalência da arte do tradutor "inscreve-se no centro de tensões contrárias entre a necessidade de reproduzir e a necessidade de criar" (Steiner apud Laranjeira 125).

Finalizando, portanto, retomando as palavras de Arrojo (427), devemos enfatizar que aquilo que se transforma em tradução é aquilo que se transforma em qualquer operação linguística dentro 
de uma mesma língua, assim as dificuldades e as multiplicidades de formas em transpor palavras e sentidos "não se destina apenas a traduções e tradutores, mas é indissociável de todo e qualquer empreendimento humano" e é o que torna os estudos tradutórios um importante caminho para o conhecimento da linguagem e da sociedade.

\section{Referências}

Achcar, F. Lírica e Lugar-Comum: Alguns Temas de Horácio e sua Presença em Português. São Paulo: EDUSP, 1994.

Arrojo, R. "Tradução." In: Jobrim, J. L. Palavras da Crítica. Rio de Janeiro: Imago, 1992.

Aulete, C. Aulete Digital - Dicionário Contemporâneo da Língua Portuguesa. Dicionário Caudas Aulete, Lexikon, 2007. 10/05/2018. < http://www.aulete. com.br/advir >

Campos, A. “Ode 1,11.” In: Código 10. Salvador, Bahia. dez. 1985a.

Campos, A. de. Ezra Pound: "Nec Spe Nec Metu" (introdução). In: Pound, E. Poesia. Trad. de Augusto de Campos [et all]; textos críticos de Haroldo de Campos. São Paulo: Hucitec, 1993b: 13-40.

Campos, A. Crisantempo: no espaço curvo nasce um. São Paulo: Perspectiva, $1998 \mathrm{c}$.

Campos, H. "Da Tradução Como Criação e Como Crítica." In: Campos, H. Metalinguagem e Outras Metas. São Paulo: Perspectiva, 2010: 31-48. 
Cardoso, Z. de A. A literatura latina. São Paulo: Martins Fontes, 2011.

Davidson, P. Ezra Pound and Roman Poetry: A Preliminary Survey. Amsterdam: Rodopi, 1995.

Faleiros, A. Traduzir o Poema. Cotia: Ateliê Editorial, 2012.

Horace. Horace, Odes et Epodes. Trad. F. Villeneuve. Paris: Les Belles Lettres, 2002a.

Horace. The Odes of Horace. Trad. Jefrey H. Kaimowitz. Introd. Ronnie Ancona. New York: The Johns Hopkins University Press, 2008b.

Laranjeira, M. Poética da tradução. São Paulo: EDUSP, 2003.

Leite, E. R. Leminski: o Poeta da Diferença. São Paulo: EDUSP, 2012.

Leminski, P. "Ode X $(1,11)$." In: Remate de Males: Território da tradução. Campinas. dez. 1984a.

Leminski, P. Ensaio e Anseios Crípticos. Campinas: Editora Unicamp, 2012b.

Leminski, P., Bonvicino, R. Envie Meu Dicionário: Cartas e Alguma Crítica. São Paulo: Editora 34, 1999.

Longo. G. Ensino de latim: reflexão e método. Araraquara: Tese (Doutorado em Linguística e Língua Portuguesa). Universidade Estadual Paulista, Faculdade de Ciências e Letras, Campus de Araraquara, 2011.

Nisbet, R. G. M., Rudd, N. A Commentary on Horace: Odes Book III. Oxford: Oxford University Press, 2004.

Pound, E. Translations. New York: New Directions, 1969. 
Santana, I. J. Paulo Leminski: Intersemiose e Carnavalização na Tradução. São Paulo: (Dissertação de Mestrado em Estudos da Tradução). Faculdade de Filosofia, Letras e Ciências Humanas, Universidade de São Paulo, 2002.

Santana, I. J.; Galindo, C. W. James Paulo Joyce Leminski. In: Sandman. M. Müller. A. [et al.]. A pau e pedra a fogo e pique: dez estudos sobre a obra de Paulo Leminski. Curitiba: Imprensa Oficial, 2010. p. 77-101.

Saraiva, F. R. S. Novíssimo Dicionário Latino-Português. Belo Horizonte; Rio de Janeiro: Livraria Garnier, 2006.

Recebido em: $25 / 11 / 2018$ Aceito em: 08/03/2019 Publicado em maio de 2019

Lívia Mendes Pereira. E-mail: liviamendesletras@gmail.com. ORCID: https:// orcid.org/0000-0002-9486-3557 